\title{
PEMERIKSAAN KADAR MERKURI DAN KELUHAN KESEHATAN DALAM DARAH WANITA PEMAKAI KRIM PEMUTIH DENGAN METODA INDUCTIVELY COUPLED PLASMA
}

\author{
Dyna Putri Mayaserli, Weni Sasmita \\ Sekolah Tinggi Ilmu Kesehatan Perintis Padang \\ Jalan Adinegoro KM 17 Simpang Kalumpang Padang \\ Email:dyna2205@yahoo.com
}

\begin{abstract}
Whitening cream is a mixture of chemicals or other materials that serve to lighten skin or fade black spots on the skin. Bleaching creams that contain mercury is very harmful for health. The purpose of this study is to examine and establish the levels of mercury in the blood of women users of whitening creams in the city of Padang. Blood samples examined as many as 10 samples and whitening creams as much as 5 samples. The qualitative analysis of the bleaching creams done with color test method, while the quantitative analysis of the blood samples used method ICP (Inductively Coupled Plasma). The results showed that of the five samples examined bleaching creams with color test, there are three positive samples contain mercury. while the results showed that the ten blood samples studied one sample contained mercury levels in the blood exceeds the normal value is $0.04435 \mathrm{mg} / \mathrm{L}$. The use of whitening creams containing mercury can cause a variety of health complaints, ranging from skin discoloration, which in turn can cause black spots on the skin, allergies, skin irritation as well as the use of high doses can cause permanent brain damage, and can cause cancer.
\end{abstract}

Key words: cream bleach, mercury, inductively coupled plasma

\section{PENDAHULUAN}

Kosmetik sejak dulu dikenal sebagai penunjang penampilan agar tampak lebih menarik. Seiring dengan berkembangnya ilmu pengetahuan dan teknologi, beragam kosmetik muncul di pasaran. Namun tidak semua kosmetik itu memenuhi aturan farmasetika yaitu, aman, berkhasiat, dan berkualitas (Wasitaatmadja, 1997). Masyarakat menganggap bahwa kosmetik tidak akan menimbulkan hal-hal yang membahayakan karena hanya ditempelkan dibagian luar kulit saja, pendapat ini tentu saja salah karena ternyata kulit mampu menyerap bahan yang melekat pada kulit. Absorpsi kosmetik melalui kulit terjadi karena kulit mempunyai celah anatomis yang dapat menjadi jalan masuk zatzat yang melekat diatasnya. Dampak dari absorpsi ini ialah efek samping kosmetik yang dapat berlanjut menjadi efek toksik kosmetik (Wasitaatmadja, 1997).

Produk pemutih wajah saat ini banyak digunakan, bukan hanya produknya yang membanjiri pasaran, tetapi juga karena dampak dari pemakaian produk tersebut. Konsumen harus berhati-hati dalam memilih kosmetik pemutih wajah, karena tidak semua produk pemutih wajah yang beredar di masyarakat aman untuk dikonsumsi. Penelitian yang dilakukan YPKKI (Yayasan Pemberdayaan Konsumen Kesehatan Indonesia) pada bulan April tahun 2002 terhadap 27 produk pemutih wajah dan anti kerut yang beredar dipasaran, ternyata kebanyakan dari produk tersebut masih dalam kategori obat. Hasil penelitian yang dilakukan oleh Yayasan Lembaga Konsumen Indonesia (YLKI) dari 20 merek yang dijadikan 
sampel yang diteliti menunjukkan ada lima merk kosmetik pemutih wajah yang telah terdaftar tetapi masih mengandung merkuri, meskipun kadarnya kecil (Rina, 2007).

Merkuri pada kosmetik yang sudah umum digunakan ialah merkuri klorida (Ralph, 1982). Mekanisme kerja senyawa merkuri dalam memutihkan kulit berbeda-beda tergantung dari jenis senyawanya. Merkuri klorida didalam kulit akan melepaskan asam klorida yang menyebabkan terjadinya pengelupasan kulit lapisan epidermis, sedangkan senyawa merkuri amino klorida memiliki aktivitas menghambat kerja enzim tirosinase yang berperan dalam proses pembentukan melanin. Melanin adalah pigmen coklat tua yang dihasilkan oleh melanosit dan disimpan dalam sel-sel epidermis kulit (Andrew \& Domonkos, 1983) yang mempunyai fungsi sebagai pelindung epidermis dan dermis dari bahaya radiasi ultraviolet (Harahap, 2000).

Merkuri termasuk logam berat berbahaya, yang dalam konsentrasi kecilpun dapat bersifat racun. Pemakaian merkuri dalam krim pemutih dapat menimbulkan berbagai hal, mulai dari perubahan warna kulit yang pada akhirnya dapat menyebabkan bintik-bintik hitam pada kulit, alergi, iritasi kulit serta pemakaian dengan dosis tinggi dapat menyebabkan kerusakan permanen otak, ginjal, dan gangguan perkembangan janin bahkan paparan jangka pendek dalam dosis tinggi juga dapat menyebabkan muntah-muntah, diare dan kerusakan paru-paru serta merupakan zat karsinogenik (dapat menyebabkan kanker) pada manusia (BPOM, 2006).

Metoda yang digunakan untuk pengukuran kadar merkuri tersebut adalah ICP (Inductively Coupled Plasma). ICP merupakan alat untuk penentuan logam dalam berbagai matriks sampel yang berbeda. ICP dikembangkan untuk spektrometri emisi optik oleh Fassel et al. di Albright \& Wilson, Ltd, Inggris pada pertengahan 1960-an. Teknik ini didasarkan pada emisi spontan foton dari atom dan ion yang telah tereksitasi dalam radio frequency (RF) discharge. Sampel cair dan gas dapat diinjeksikan langsung ke instrumen, sedangkan sampel padat memerlukan ekstraksi atau digesti asam sehingga analit akan di dapatkan dalam bentuk larutan.

Tujuan penelitian ini adalah untuk mengukur kadar logam Merkuri (Hg) pada krim pemutih dan sampel darah wanita yang menggunakan krim pemutih tersebut dengan menggunakan Metoda ICP (Inductively Coupled Plasma) dan keluhan kesehatan yang ditimbulkan akibat pemakaian krim pemutih tersebut.

\section{METODE PENELITIAN}

Alat yang digunakan ICP E 9000 Shimadzu, gelas ukur $10 \mathrm{~mL}$, beaker glass 50 $\mathrm{mL}$, hot plate, peralatan gelas, spuit, kapas alkohol $70 \%$. Bahan yang digunakan sampel darah, sampel krim pemutih, Asam Nitrat pekat $\left(\mathrm{HNO}_{3}\right)$, peroksida $\left(\mathrm{H}_{2} \mathrm{O}_{2}\right)$, larutan standar merkuri $(\mathrm{Hg}), \mathrm{KI} 0,5 \mathrm{~N}$, aquadest, antikoagulan EDTA

\section{Pembuatan Larutan Standar Merkuri (Hg)}

Larutan standar dibuat dari larutan standar dengan konsentrasi $1000 \mathrm{mg} / \mathrm{L}$. Lalu dibuat deret larutan standar dengan konsentrasi $0,02 \mathrm{mg} / \mathrm{L}, 0,04 \mathrm{mg} / \mathrm{L}, 0,06 \mathrm{mg} / \mathrm{L}, 0,08 \mathrm{mg} / \mathrm{L}$ dan $0,1 \mathrm{mg} / \mathrm{L}$. Dibaca absorbannya pada ICP (Inductively Coupled Plasma) pada panjang gelombang 253,7 $\mathrm{nm}$.

\section{Persiapan sampel darah}

Sampel darah diambil dari vena lengan dengan mengggunakan tabung vacum tutup ungu yang telah mengandung antikoagulan EDTA sebanyak $5 \mathrm{ml}$, bila tidak bisa melakukan pemeriksaan secara langsung, sampel dapat disimpan didalam freezer dengan suhu $18^{\circ} \mathrm{C}$ sampai $20^{\circ} \mathrm{C}$

\section{Pembuatan Larutan Uji}

Ditimbang dengan teliti sebanyak $2 \mathrm{~g}$ sampel. Ditambahkan air sebanyak $25 \mathrm{ml}$, setelah itu tambahkan dengan campuran $10 \mathrm{ml}$ larutan asam klorida dan asam nitrat, lalu uapkan sampai hampir kering. Pada sisa penguapan tambahkan akuades sebanyak $10 \mathrm{ml}$. Lalu dipanaskan sebentar, didinginkan dan disaring.

\section{Uji kualitatif Sampel Krim Pemutih}


$1 \mathrm{ml}$ larutan uji ditambahkan 1-2 tetes larutan $\mathrm{KI} 0,5 \mathrm{~N}$, lalu diperhatikan dengan saksama. Hasil menunjukkan positif jika terjadi endapan merah orange.

\section{Uji kuantitatif Sampel Darah}

Sampel di destruksi basah dengan cara ambil sampel $5 \mathrm{ml}$ kemudian tambahkan $5 \mathrm{ml}$ asam nitrat. Panaskan di hotplate pada suhu 90 $120^{\circ} \mathrm{C}$ sampai uap kuningnya hilang, kira-kira selama 3 jam. Kemudian tambahkan peroksida $3 \mathrm{ml}$, panaskan lagi 15 menit sampai didapatkan larutan kuning jernih. Dinginkan, saring dan paskan volumenya $10 \mathrm{ml}$. kemudian, diukur absorbansinya pada ICP dengan panjang gelombang $253,7 \mathrm{~nm}$

\section{HASIL DAN PEMBAHASAN}

\section{Analisis Kualitatif Merkuri (Hg) Uji Warna}

Analisis kualitatif merkuri didalam krim pemutih wajah terhadap sampel A, B, C, D, E dilakukan dengan menggunakan metode uji warna. Bertujuan untuk mengidentifikasi ada atau tidaknya merkuri dalam sampel dengan cara menambahkan 1-2 tetes larutan KI 0,5 N.

Tabel 1. Hasil Analisis Kualitatif Merkuri dengan Larutan KI 0,5 N

\begin{tabular}{ccc}
\hline No & Nama Sampel & Reaksi dengan Larutan KI 0,5 N \\
\hline 1. & A & Negatif \\
2. & B & Positif \\
3. & C & Positif \\
4. & D & Negatif \\
5. & E & Positif \\
\hline
\end{tabular}

Hasil menunjukkan positif jika terjadi endapan merah orange. Hasil penelitian dari kelima sampel yang diuji terdapat tiga sampel yang positif mengandung merkuri yaitu sampel B, C, E sedangkan sampel A, D negatif tidak mengandung merkuri. Selanjutnya sampel yang positif mengandung merkuri akan diuji kadarnya pada darah wanita yang memakai krim pemutih tersebut. Dari 5 sampel krim pemutih yang diuji ada $3 \mathrm{krim}$ pemutih yang tidak terdapat nomor BPOM dengan arti kata komposisi dari krim pemutih belum tentu sesuai dengan standar yang telah ditetakan oleh BPOM. Pemutih tidak memiliki komposisi pada kemasan, tapi masih beredar di masyarakat. Seharusnya di lakukan pemeriksaan oleh BPOM sebelum dilakukan pengedaran produkproduk krim pemutih di masyarakat, karena bahaya krim pemutih yang mengandung merkuri apabila digunakan dalam waktu yang lama maka akan mengakibatkan iritasi kulit bahkan dapat menyebabkan kanker kulit.

\section{Analisis Kuantitatif Merkuri (Hg) dengan Metode ICP}

Hasil pemeriksaan logam merkuri $(\mathrm{Hg})$ pada darah wanita pemakai krim pemutih yang berada di Kota Padang dengan menggunakan metode ICP (Inductively Coupled Plasma) dapat dilihat pada Tabel 2.

Analisis kuantitatif merkuri didalam darah terhadap sampel A, B, C, D, E, F, G, H, I, $\mathrm{J}$, dilakukan dengan menggunakan metode ICP (Inductively Couple Plasma) dengan panjang gelombang $253,75 \mathrm{~nm}$. Hasil penelitian dari kesepuluh sampel darah wanita pemakai krim pemutih tersebut terdapat satu sampel yang kadarnya melebihi ketetapan PERMENKES RI No. 445/MENKES/PER/V/1998 yaitu sampel E dengan kadar $0,04435 \mathrm{mg} / \mathrm{L}$, sedangkan sampel A, B, C, D, F, G, H, I, J masih berada dalam batas normal yaitu dibawah $0,04 \mathrm{mg} / \mathrm{L}$. 
Tabel 2. Hasil Hasil Analisis Kuantitatif Logam Merkuri (Hg) pada Kosmetik Krim Pemutih

\begin{tabular}{crrc}
\hline No & Kode Sampel Darah & Kadar $(\mathrm{mg} / \mathrm{L})$ & Kode Krim Pemutih \\
\hline 1. & $\mathrm{~A}$ & 0,01259 & $\mathrm{C}$ \\
2. & $\mathrm{~B}$ & 0,02415 & $\mathrm{~B}$ \\
3. & $\mathrm{C}$ & 0,01176 & $\mathrm{~B}$ \\
4. & $\mathrm{D}$ & 0,02108 & $\mathrm{C}$ \\
5. & $\mathrm{E}$ & 0,04435 & $\mathrm{E}$ \\
6. & $\mathrm{~F}$ & 0,02417 & $\mathrm{C}$ \\
7. & $\mathrm{G}$ & 0,02813 & $\mathrm{~B}$ \\
8. & $\mathrm{H}$ & 0,02325 & $\mathrm{C}$ \\
9. & $\mathrm{I}$ & 0,03147 & $\mathrm{E}$ \\
10. & $\mathrm{~J}$ & 0,01474 & $\mathrm{E}$ \\
\hline
\end{tabular}

Dari uji statistik yang dilakukan yaitu uji $\mathrm{t}$, didapatkan nilai $\mathrm{t}$ hitung $>$ nilai $\mathrm{t}$ tabel yang berarti Ho ditolak dan Ha diterima. Maka kadar merkuri dalam darah wanita pemakai krim pemutih tidak melebihi batas kadar yang telah ditentukan oleh PERMENKES RI No. 445/MENKES/PER/V/1998. tentang daftar bahan, zat warna, substratum, zat pengawet dan tabir surya pada kosmetik, menyatakan bahwa raksa dan senyawanya dilarang digunakan dalam kosmetik

Dalam melakukan uji warna bertujuan untuk mengidentifikasi ada atau tidaknya merkuri dalam sampel krim pemutih digunakan larutan KI 0,5 N, hasil menunjukan positif jika terjadi endapan merah orange, sedangkan metode Inductively Coupled Plasma digunakan untuk mengukur absorban suatu sampel sebagai fungsi panjang gelombang.

Tabel 3. Hasil pengukuran serapan beberapa konsentrasi larutan standar $\mathrm{Hg}$ pada panjang gelombang $253,7 \mathrm{~nm}$.

\begin{tabular}{cc}
\hline Concentration in $\mathrm{mg} / \mathrm{L}$ & Intensity \\
\hline 0 & 0,000000 \\
0,02 & 0,085435 \\
0,04 & 0,176570 \\
0,06 & 0,245379 \\
0,08 & 0,328760 \\
0,10 & 0,417680 \\
\hline
\end{tabular}

Kurva kalibrasi merupakan metode yang banyak digunakan untuk penentuan konsentrasi analit serta menunjukkan kelinearan pengukuran, yaitu dari persamaan regresi kurva, yang ditunjukan dengan nilai koefisien korelasi
(R2) dari persamaan regresi kurva yang mendekati nilai 1. Inrtersep yang dihasilkan pada persamaan regresi menunjukkan akurasi dari metode pengukuran yang digunakan. Jika persamaan regresi linier menghasilkan intersep 
dengan nilai mendekati nol, maka dapat dikatakan metode pengukuran akurat. Dengan kata lain, kalibrasiadalah kegiatan untuk menentukan kebenaran konvensional nilai penunjukkan alat ukur dan bahan ukur dengan cara membandingkan terhadap standar ukur yang mampu telusur (traceable) ke standar nasional untuk satuan ukuran dan/atau internasional. Hasil kalibrasi dapat dilihat pada gambar 1.

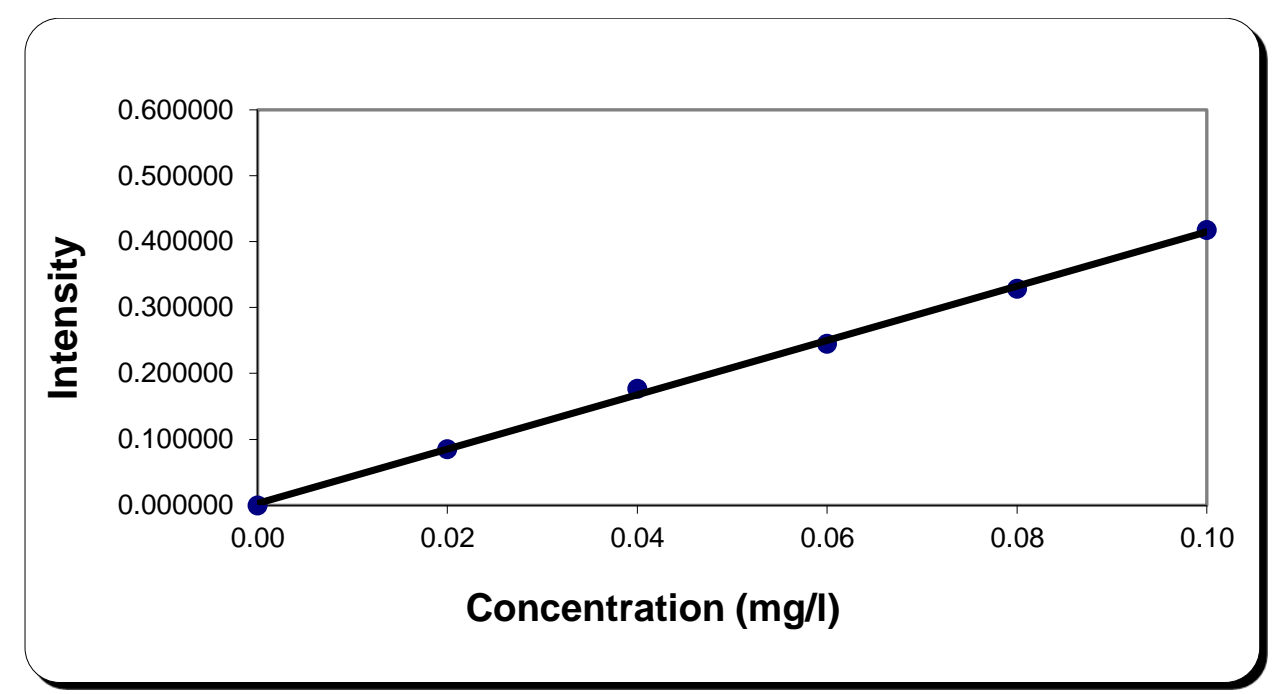

Gambar 1. Kurva kalibrasi antara serapan dengan beberapa konsentrasi standar $\mathrm{Hg}$

\section{Analisis Keluhan Kesehatan}

Kadar merkuri pada responden tidak melebihi batas yang telah ditetapkan. Hal ini bias disebabkan oleh makanan yang dikonsumsi oleh responden seperti sayur-sayuran, buahbuahan yang mengandung vitamin dan mineral dapat mendegregasikan logam merkuri. Kemudian didetoksifikasi melalui urin, tinja, dan keringat dengan menggunakan empat organ utama yaitu, hati, ginjal, saluran pencernaan, dan kulit.

Dari kesepuluh sampel darah wanita pemakai krim pemutih, terdapat dua sampel yang kadar merkurinya paling sedikit dikarenakan produk kosmetik yang digunakannya sedikit mengandung merkuri. Hampir 50\% dari wanita pemakai krim pemutih telah menggunakan krim pemutih wajah selama lebih dari tiga tahun. Lamanya pemakaian produk krim pemutih yang mengandung merkuri menyebabkan ketergantungan yang apabila dihentikan akan timbul jerawat, bintikbintik merah, iritasi serta rasa gatal.

Wanita yang menggunakan krim pemutih wajah yang mengandung merkuri akan membuat wajah terlihat putih bersih, dapat menghilangkan jerawat, pori-pori mengecil dan kulit menjadi lebih halus. Hal ini disebabkan lapisan kulit terluar yaitu bagian epidermis telah menipis oleh logam berat. Apabila terlalu lama terpapar dengan sinar matahari maka kulit terasa panas, gatal, dan wajah menjadi merah. Hal ini dikarenakan kulit wajah sudah tidak mendapat perlindungan dari melanin yang berfungsi melindungi wajah dari sinar matahari, apabila kulit yang bagian epidermis telah menipis dan selalu terpapar oleh sinar UV (Ultra Violet) maka dapat menyebabkan kanker kulit.

Kurangnya pengetahuan tentang produk kosmetik wajah yang baik dan aman untuk kesehatan membuat sebagian orang masih tetap menggunakan krim pemutih yang mengandung 
merkuri. Namun, tidak sedikit pula dari mereka yang telah mengetahui tentang bahaya pemakaian krim pemutih yang mengandung merkuri justru memilih untuk tetap memakainya. Dengan alasan untuk mempercantik diri dalam waktu yang singkat, tanpa memikirkan efek samping dan bahaya yang ditimbulkan terhadap kesehatan akibat dari pemakaian krim pemutih yang mengandung merkuri. Akumulasi merkuri dalam tubuh akan menyebabkan terjadinya regenerasi sel-sel saraf di otak kecil yang menguasai koordinasi saraf dan degenerasi sarung selaput saraf, yang akhirnya bisa menyebabkan kelumpuhan dan kematian.

Sampel yang terdeteksi merkuri adalah sampel yang beredar dimasyarakat dan dijual bebas baik di pasaran maupun di toko. Hal ini seharusnya diperhatikan oleh pemerintah dalam mengedarkan berbagai produk-produk pemutih wajah, karena ketiga krim pemutih wajah yang positif mengandung merkuri sudah sangat jelas tidak memiliki nomor POM maupun nomor batch. Adapun dari kelima sampel yang diteliti, beberapa sampel krim pemutih tidak memiliki komposisi pada kemasan, tetapi masih beredar di masyarakat. Seharusnya dilakukan pemeriksaan oleh BPOM sebelum dilakukan pengedaran produk-produk krim pemutih di masyarakat, karena bahaya krim pemutih yang mengandung merkuri apabila digunakan dalam waktu yang lama maka akan mengakibatkan iritasi kulit bahkan dapat menyebabkan kanker kulit (Parengkuan, 2013).

\section{KESIMPULAN}

Dari penelitian yang telah dilakukan dapat dsimpulkan :

1. Hasil penelitian secara kualitatif dari kelima sampel krim pemutih terdapat tiga sampel yang mengandung merkuri yaitu sampel $B$, $\mathrm{C}$, E yang ditandai dengan terbentuknya endapan berwarna merah orange. Hasil penelitian secara kuantitatif dari kesepuluh sampel darah wanita pemakai krim pemutih terdapat satu sampel yang kadarnya melebihi ketetapan PERMENKES RI No. 445/MENKES/PER/V/1998 yaitu sampel E dengan kadar $0,04435 \mathrm{mg} / \mathrm{L}$, sedangkan sampel A, B, C, D, F, G, H, I, J masih berada dalam batas normal yaitu dibawah $0,04 \mathrm{mg} / \mathrm{L}$.

2. Pemakaian merkuri dalam krim pemutih dapat menimbulkan berbagai keluhan kesehatan, mulai dari perubahan warna kulit yang pada akhirnya dapat menyebabkan bintik-bintik hitam pada kulit, alergi, serta iritasi kulit.

\section{DAFTAR KEPUSTAKAAN}

Andrew GC \& Domonkos AN. 1983. Disease of The Skin: For Practitioner and Student. Philadelphia: W.B. Saunders Company.

Boss CB dan Kenneth JF. 1997. Concepts, Instrumentation, and Techniques in Inductively Coupled Plasma Optical Emission Spectrometry, Second Edition. USA: Perkin Elmer.

Erasiska. 2015. Analisis Kandungan Logam Timbal, Kadmium Dan Merkuri Dalam Produk Krim Pemutih Wajah. Jurnal fakultas MIFA, Vol2, No 1.

Fina YG, Daulay. 2005. Analisa Kadar Logam Berat Merkuri (Hg) Pada Beberapa Produk Kosmetik Krim Pemutih China yang Beredar di Pasaran Kota Medan. Skripsi. FKM. Medan.

Harahap M. 2000. Ilmu Penyakit Kulit. Jakarta: Hipokrates.

Hou X dan Bradley TJ. 2000. Inductively Coupled Plasmal Optical Emission Spectrometry. Chichester: John Wiley \& Sons Ltd.

Jaelani. 2009. Ensiklopedi Kosmetika Nabati. Edisi pertama. Jakarta: Pustaka Populer Obat.

Kristianingrum S. 2004. Kegiatan Pelatihan Penggunaan dan Perawatan Alat-alat Laboratorium Kimia. Fakultas MIFA, Universitas Negeri Yogyakarta.

Palar H. 2012. Pencemaran Dan Toksikologi Logam Berat. Jakarta: Rineke Cipta.

Ralph GH. 1982. Harry's Cosmeticology. New York: Chemical Publishing Company Inc. 
Mayaserli, D. P., \& Sasmita, W. 2016. Pemeriksaan Kadar Merkuri dan Keluhan Kesehatan dalam Darah Wanita Pemakai Krim Pemutih dengan Metoda Inductively Coupled Plasma. Journal of Sainstek 8(2): 159-165

Sartono. 2001. Racun dan keracunan. Jakarta: Widya Medika.

Skoog DA, Donald MW, F James H, Stanley RC. 2000. Fundamentals og Analytical Chemistry. Hardcover. 992 pages, publisher. Brookscole.

Rina M, Sunarko. 2007. Analisis unsur-unsur toksik dalam sampel krim pemutih wajah dengan metode analisis aktivasi neutron. Jurnal PTBIN: BATAN.

Wasitaatmadja SM. 1997. Penuntun Ilmu Kosmetik Medik. Jakarta: Universitas Indonesia.

Widowati, Wahyu. 2008. Efek Toksik Logam. Andi: Yogyakarta. 